Engineering Heat Transfer 
Other Macmillan Education titles of related interest

An Introduction to Engineering Fluid Mechanics

J. A. Fox

Principles of Engineering Thermodynamics

E. M. Goodger 


\title{
Engineering Heat Transfer
}

\author{
J. R. Simonson
}

Senior Lecturer in Applied Thermodynamics

The City University, London 
ISBN 978-0-333-18757-9 ISBN 978-1-349-15605-4 (eBook)

DOI 10.1007/978-1-349-15605-4

(C) J. R. Simonson 1975

Softcover reprint of the hardcover 1st edition 1975 978-0-333-18213-0

All rights reserved. No part of this publication may be reproduced or transmitted, in any form or by any means, without permission.

First published 1975 by

THE MACMILLAN PRESS LTD

London and Basingstoke

Associated companies in New York Dublin

Melbourne Johannesburg and Madras

SBN 333182138 (hard cover)

333187571 (paper cover)

This book is sold subject to the standard conditions of the Net Book Agreement.

The paperback edition of this book is sold subject to the condition that it shall not by way of trade or otherwise, be lent, re-sold hired out, or otherwise circulated without the publisher's prior consent in any form of binding or cover other than which it is published and without a similar condition being imposed on the subsequent purchaser. 


\section{Contents}

Preface

ix

Nomenclature

$\mathrm{xi}$

1 Introduction 1

2 The Equations of Heat Conduction $\quad 8$

2.1 The Nature of Heat Conduction 8

2.2 The Differential Equation of Conduction in a Cartesian Coordinate System

2.3 The Differential Equation of Conduction in a Cylindrical Coordinate System

3 One-dimensional Steady State Conduction

3.1 Conduction in Plane Slabs 16

3.2 Effect of a Variable Conductivity in a Plane Slab 22

3.3 Radial Conduction in Cylindrical Layers 23

3.4 Critical Thickness of Insulation 26

3.5 Radial Conduction in Spherical Layers $\quad 27$

3.6 Conduction with Heat Sources 27

4 Two-dimensional Steady State Conduction 35

4.1 A Numerical Solution to Two-dimensional Conduction 36

4.2 Elementary Computing Procedures for Two-dimensional Steady State Conduction

4.3 The Electrical Analogy of Two-dimensional Conduction 46

5 Transient Conduction $\quad 52$

5.1 The Uniform Temperature, or Lumped Capacity, System 52

5.2 The Solution of Transient Conduction Problems in One Dimension

5.3 Two-dimensional Transient Conduction 61

5.4 Periodic Temperature Changes at a Surface 62

6 Forced Convection: Boundary Layer Principles 72

6.1 Introduction 72

6.2 Equations of the Laminar Boundary Layer on a Flat Plate 74

6.3 Laminar Forced Convection on a Flat Plate 81

6.4 Laminar Forced Convection in a Tube 86 
7 Forced Convection: Reynolds Analogy and Dimensional Analysis

7.1 Reynolds Analogy

7.2 Dimensional Analysis of Forced Convection

7.3 Empirical Relationships for Forced Convection

8 Natural Convection

8.1 The Body Force

8.2 Dimensional Analysis of Natural Convection

8.3 Formulae for the Prediction of Natural Convection

9 Separated Flow Convection

9.1 Relationship between Heat Transfer and Pressure Loss in a Complex Flow System

9.2 Convection from a Single Cylinder in Cross Flow

9.3 Convection in Flow across Tube Bundles

10 Convection with Phase Change

10.1 Description of Condensing Flow

10.2 A Theoretical Model of Condensing Flow 134

10.3 Boiling Heat Transfer

11 Mass Transfer by Convection

11.1 Mass and Mole Concentrations

11.2 Molecular Diffusion

11.3 Eddy Diffusion

11.4 Molecular Diffusion from an Evaporating Fluid Surface

11.5 Mass Transfer in Laminar and Turbulant Convection

11.6 Reynolds Analogy

11.7 Combined Heat and Mass Transfer

12 Extended Surfaces

12.1 The Straight Fin and Spine

12.2 Limit of Usefulness of the Straight Fin 167

12.3 Fin and Finned Surface Effectiveness 167

12.4 Overall Coefficients of Finned Surfaces 169

12.5 Numerical Relationships for Fins 172

13 Heat Exchangers 178

13.1 Types of Heat Exchanger, and Definitions 178

13.2 Determination of Heat Exchanger Performance 183 
13.3 Heat Exchanger Transfer Units 187

13.4 Plate Heat Exchangers 193

14 The Laws of Black- and Grey-body Radiation 200

14.1 Absorption and Reflection of Radiant Energy 201

14.2 Emission, Radiosity and Irradiation 202

14.4 Black and Non-black Bodies 202

14.4 Kirchoff's Law 205

14.5 Intensity of Radiation 207

14.6 Radiation Exchange Between Black Surfaces 209

14.7 Grey-body Radiation Exchanges 214

14.8 Non-luminous Gas Radiation 218

14.9 Solar Radiation 221

Appendix 1 Heat Transfer Literature 226

$\begin{array}{lll}\text { Appendix } 2 \text { Units and Conversion Factors } & 227\end{array}$

Appendix 3 Tables of Property Values 230

Appendix 4 Gas Emissivities $\quad 247$

$\begin{array}{ll}\text { Index } & 251\end{array}$ 


\section{Preface}

The aim of this book, which is a revised edition of a book previously published by McGraw-Hill, is to introduce the reader to the subject of heat transfer. It will take him sufficiently along the road to enable him to start reading profitably the many more extensive texts on the subject, and the latest research papers to be found in scientific periodicals. This book is therefore intended for students of engineering in universities and technical colleges, and it will also be of assistance to the practising engineer who needs a concise reference to the fundamental principles of the subject. The engineering student will find most, if not all, aspects of the subject taught in undergraduate courses and, thus equipped, he will be in a position to undertake further studies at postgraduate level.

The aim throughout has been to introduce the principles of heat transfer in simple and logical steps. The need for an easily assimilated introduction to a subject becomes more urgent when the subject itself continues to grow at an ever-increasing rate. It is hoped that the material selected and presented will be of value at all levels of readership. Indebtedness is acknowledged to all those, past and present, who have contributed to the science of heat transfer with their original work, and as far as possible detailed references are given at the end of each chapter. Also grateful thanks are extended to various persons and organizations for permission to use certain diagrams, tables, and photographs; credit for these is given at appropriate points throughout the text.

It is also hoped that in this edition the changes made will further enhance the value of the book. Greater attention has been given to numerical methods in conduction, and some basic procedures in digital computing are included The chapter on radiation has been extended to include an introduction to non-luminous gas radiation and a short section on solar radiation. Numerous small changes have 
been made throughout in the light of reviews and criticisms received. New worked examples are included to extend the range of applicability, and some of the original problems set have been replaced by more recent ones. SI units are now used exclusively, and conversion factors for British units are included in appendix 2.

Many of the problems included are university examination questions; the source is stated in each case. Where necessary the units in the numerical examples have been converted to SI. Indebtedness is acknowledged to the owners of the copyright of these questions for permission to use them, and for permission to convert the units. The universities concerned are in no way committed to the approval of numerical answers quoted.

Much of the material in this book has been taught for a number of years at undergraduate level to students at The City University. Grateful thanks are due to Professor J. C. Levy, Head of the Department of Mechanical Engineering, and to Mr B. M. Hayward, Head of the Thermodynamics Section. Discussions with colleagues at City and elsewhere have also contributed in numerous ways, and for this help sincere thanks are expressed.

Finally, thanks are due to Malcom Stewart, of The Macmillan Press, who has been responsible for the production of both editions, and also to my wife, who has typed the manuscript revisions. 


\section{Nomenclature}

\begin{tabular}{|c|c|}
\hline$a$ & distance increment \\
\hline$A$ & area \\
\hline$b, l, t, w$ & linear dimension \\
\hline$c$ & concentration \\
\hline C & capacity ratio of heat exchanger \\
\hline$C, K$ & constants of integration \\
\hline$C d$ & average friction factor \\
\hline$C f$ & skin friction coefficient \\
\hline$c_{\mathrm{p}}$ & specific heat at constant pressure \\
\hline $\begin{array}{l}C_{\mathrm{p}} \\
d\end{array}$ & $\begin{array}{l}\text { volumetric specific heat at constant pressure } \\
\text { diameter }\end{array}$ \\
\hline D & diffusion coefficient \\
\hline$E$ & effectiveness of heat exchanger \\
\hline$f$ & friction factor \\
\hline$F$ & geometric configuration factor \\
\hline$F$ & geometric emissivity factor \\
\hline$f_{\mathbf{D}}$ & drag factor \\
\hline $\mathbf{g}$ & gravitational acceleration \\
\hline$g$ & mass transfer per unit area and time \\
\hline G & irradiation, mass velocity \\
\hline$h$ & convection coefficient \\
\hline$h_{\mathrm{fg}}$ & latent enthalpy of evaporation \\
\hline$h_{\mathrm{m}}$ & mass transfer coefficient \\
\hline$h_{\mathrm{R}}$ & radiation coefficient \\
\hline$i$ & current density \\
\hline$I$ & current \\
\hline$I$ & intensity of radiation \\
\hline$J$ & radiosity \\
\hline$k$ & thermal conductivity \\
\hline$L, D, T, W$ & linear dimension \\
\hline$L, M, T, \theta$ & dimensions of length, mass, time, temperature \\
\hline $\begin{array}{l}m \\
n\end{array}$ & $\begin{array}{l}\text { mass flow, or mass in transient conduction } \\
\text { coordinate direction }\end{array}$ \\
\hline$n$ & frequency of temperature variation \\
\hline$N T U$ & number of transfer units \\
\hline$p, P, \Delta p$ & pressure, difference of pressure \\
\hline & perimeter \\
\hline PN & plate number \\
\hline$q$ & heat transfer per unit area and time \\
\hline$q^{\prime}$ & heat generation per unit volume and time \\
\hline
\end{tabular}




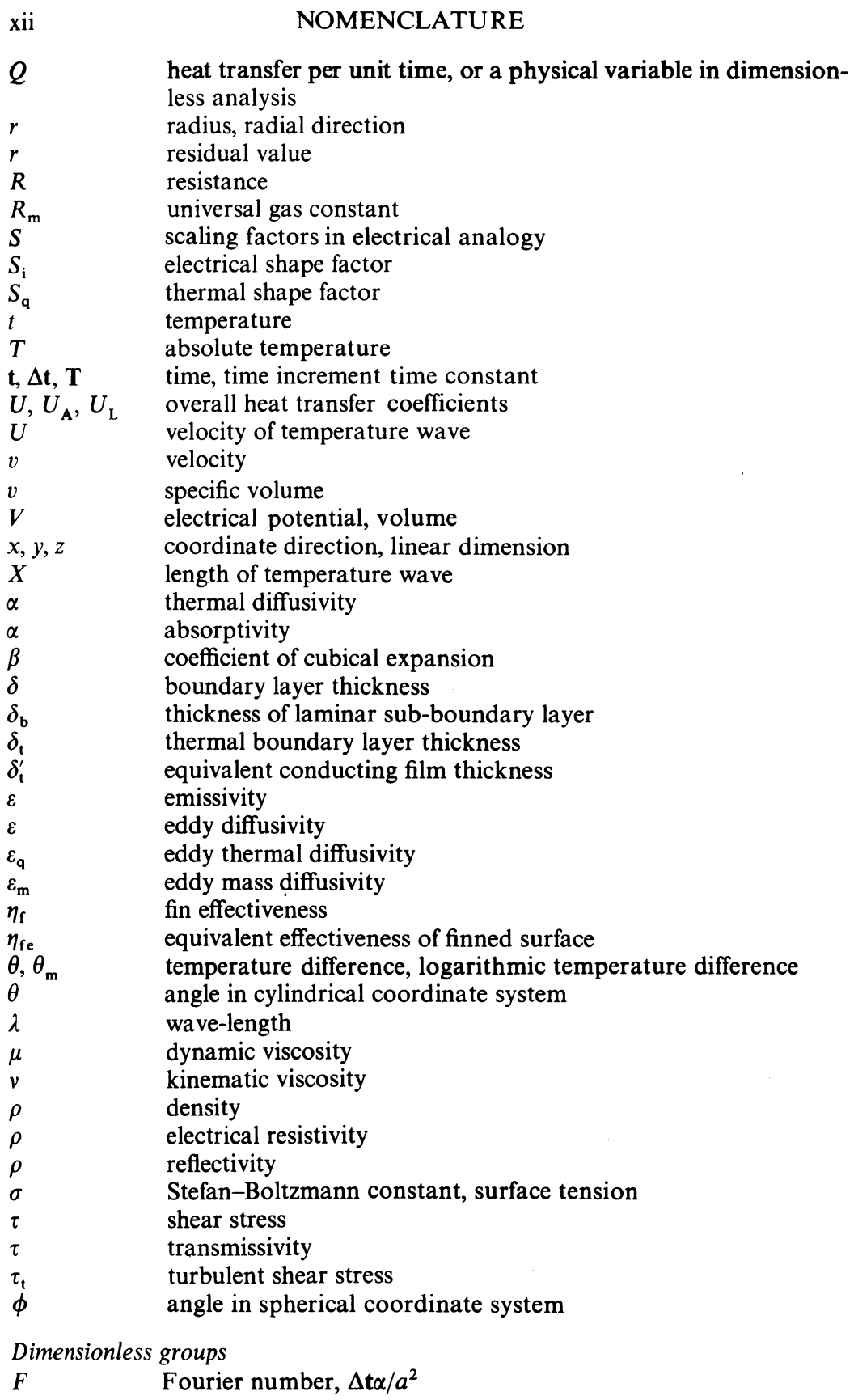

Dimensionless groups

$F \quad$ Fourier number, $\Delta \mathbf{t} \alpha / a^{2}$ 


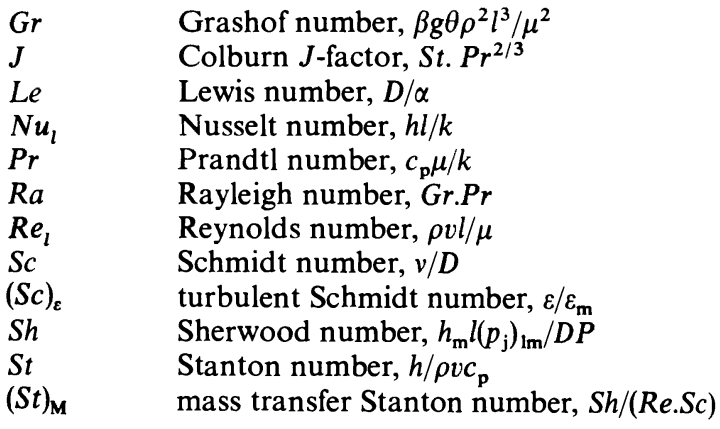

\section{Suffices}

a

a, w

b

b

c

$d, l, x$

e

f

$\mathrm{h}$

$\mathrm{i}, \mathrm{j}$

i, o

$\mathrm{m}$

$n$

0

$r$

s

sat.

$t$

w

$x, y, z$

$\theta$

$\lambda$

at axis of tube

air, water, (in hygrometry)

black body

limit of laminar sub-boundary layer

cold fluid

length terms used in dimensionless groups

equivalent

fluid

hot fluid, heated length

components of mixture (in mass transfer)

inlet, outlet, (in heat exchangers)

mean value

direction of component

datum length

radial direction, or radial position

surroundings, of free stream

saturated temperature

temperature, turbulent

wall

direction of component

angular component

monochromatic

Superscript

average value 